Original Research Paper

\title{
Impact of the Drainage Slope Experimental Study on the Manning Roughness Coefficient
}

\author{
${ }^{1 *}$ Kaveh Ostad-Ali-Askari, ${ }^{2}$ Hossein Gholami, ${ }^{3}$ Shahide Dehghan and ${ }^{4}$ Morteza Soltani \\ ${ }^{I}$ Department of Water Engineering, College of Agriculture, Isfahan University of Technology, Isfahan 84156-83111, Iran \\ ${ }^{2}$ Department of Civil Engineering, Isfahan (Khorasgan) Branch, Islamic Azad University, Isfahan, Iran \\ ${ }^{3}$ Department of Geography, Najafabad Branch, Islamic Azad University, Najafabad, Iran \\ ${ }^{4}$ Department of Architectural Engineering, Shahinshahr Branch, Islamic Azad University, Shahinshahr, Iran
}

\author{
Article history \\ Received: 10-07-2020 \\ Revised: 11-01-2021 \\ Accepted: 15-01-2021 \\ Corresponding Author: \\ Kaveh Ostad-Ali-Askari \\ Department of Water \\ Engineering, College of \\ Agriculture, Isfahan University \\ of Technology, Isfahan \\ 84156-83111, Iran \\ Email: ostadaliaskari.k@of.iut.ac.ir \\ kaveh.oaa2000@gmail.com
}

\section{Introduction}

Drainage slopes establish an important environment within the agronomic and city situation, which requirements to be conserved as significant place for vegetation and animals, some of which are imperiled species. It was planned to prepare valuable managements for working in drainage systems, as it denotes a very usual problem universal. It was situated adjacent is encountered to flood exposures, consequently the organization of drainage slopes is essential to confirm the hydraulic efficacy of the drainage system. The evaluation the impact of aquatic depth and precipitation concentration on the superficial coarseness factors was applied in overland current mockups depend on the superficial aquatic calculations. The relation amongst the Manning constant and the aquatic penetration and precipitation concentration has been measured applying diverse procedures depend on the investigation of trial information. The constant highland flow situations were made and the bed coarseness factor was calculated from straight quantities of the aquatic penetration and release. Applying a Reynolds reliant on design for the Manning Coefficient progresses model forecasts. Drainage slope patterns, as the eminent Water Management pattern are due to more refined double patterns while the superficial runoff factor is calculated with a disseminated Manning prototypical be contingent on the superficial aquatic calculations and Manning roughness constant. The bed coarseness factor diverted considerably with the water release. In nearly every calculation of highland currents with drainage slope is assessed with a persistent roughness constant, which be determined by only on the superficial variety however was not contemplated the result of aquatic penetration or precipitation concentration on the actual coarseness. Components as the aquatic penetration and the precipitation concentration could have an important effect on the operative coarseness constant. It has been determined the results of precipitation concentration on the operative coarseness factors. There is an important rise in the roughness measurement as the water drainage slope below a serious assessment. This supposition is maintained by the great Manning constants which have been described for highland current in earlier journals. The water penetration methods the dimension of the roughness elevation and consequently it does the current resistance. In General, for the planned current, rapidity and penetration of current in natural conduits, as approximations of overflow and residue current 
persistence evaluation is significant. Hydraulic persistence for open conduits and superficial currents on steep mountainous zones is a significant characteristic to define the features of hydraulic current for modeling runoff, directing overflow, flood and corrosion is the greatest significant. The persistence not individual marks to evaluate the current flexibles for example penetration and current degree then similarly the consequences of these flexibles, for example current spreading in the basin and residue transportation volume are inclined. The persistence of a superficial can be recognized by the quantity of hydraulic coarseness constant (Chen et al., 2009). The possessions that most applied in this investigation are: Manning coarseness constant $(n)$, Chezy persistence component $(c)$ and Darcy-Weisbach persistence component $(f)$. Actually, approximations of these components can support to evaluate more precise current situations. Similarly, in all numerical models were applied to evaluate the current situations for example penetration, rapidity, shear pressure and etc. in streams and open conduits that applied nowadays, it is essential to define one of the three components declared.

The resulting associations connected to the design of these constants that stated. The association amongst the mean current rapidity $(V)$ and persistence constants, symmetrical and hydraulic superficial (Chow, 1959):

$$
\begin{aligned}
& V=\frac{k n}{n} R^{2 / 3} D_{F}^{1 / 2}(\text { Manning }) \\
& V=\sqrt{\frac{8 g}{f}} \sqrt{R S}(\text { Darcy }- \text { Weisbach }) \\
& (V=C \sqrt{R S}(\text { Chezy })
\end{aligned}
$$

It was used Darcy-Weisbach components $(f)$ practice more strength designs in investigational revisions, then (n) component is the finest component for hydraulic mockups (Dash and Khatua, 2016). It was assessed the result of subordinate flexibles on the Manning coarseness components $(n)$. Components mark the Manning coarseness constant also decline or rise in the strength of hydraulic straight mark the association were significant. Dissimilar revisions and examines pointers by the way in addition to investigational modeling and scientific modeling and they are seeking associations amongst hydraulic possessions of the current in the hydraulic persistence in outside situations, mostly the current of the stream Models has been finished, then insufficient revisions have examined about surface river in zones with sharp gradient (Emmett, 1970). These revisions tried to suitable relationships by evaluation a quantity of flexibles for example the Re number, the Fr number, the roughness features, Area gradient and flora cover proportion gained in this zone (Chang et al., 2010). Most new revisions gained empirically associations with application to surface currents, network tubes and flat conduits. numerous revisions has been completed on the effect of deposit element dimensions and the frame superficial throughout the Manning coarseness coefficient (n) that Manning coarseness coefficient $(n)$ is individual a purpose of the average element size bed (Ks 1/6). In addition to many investigation has been completed about the possessions of flora on coarseness component together external and exclusive the nation in the ground of herbal-created (flora) covering coarseness depend on Fathi-Moghadam investigation for non-flooded flora and cowen investigation conferring to Nikuradse model of qualified roughness's for flora inundated. Normally, so as to choose the correct Manning coarseness factor $(n)$ must be defined the components that mark the $(n)$ advantage. These components include: superficial and fuselage coarseness, flora, asymmetrical cross-section drainage, deposit and scour, blockades, water level and current, postponed weight and bed load. The careful design of the constant $n$ by expert engineering is not possible and depends on engineering judgment, so lack of detailed estimates Manning roughness coefficient $(n)$ will reduce the efficiency of the project. Getting subject data to regulate the coarseness factor is very problematic and takes too much time and cost. So, in resolving river engineering difficulties, in many cases applied from experiential or semi-experimental or tables brigade. Roughness component has a significant character of current degree, rapidity, shear stress border and many other hydraulic components. Consequently, considerating this component is important for optimum project of open channels and other channel (Conesa-García et al., 2018).

\section{Materials and Methods}

So as to attain the determinations of this study, numerous assessments were directed in the hydraulic workshop Shahid Chamran College, Ahvaz, Iran. This workshop has a foremost reservoir, that community water system be fedand then reservoirs water shifted into the flume by pump through a pipe with a diameter of three hundred millimeter, then a split d63 $\mathrm{mm}$. The flume applied in the experimentations in this training has a length of 3.8 $\mathrm{m}$, width $80 \mathrm{~cm}$, depth $50 \mathrm{~cm}$ and gradient was 0.0005 that its construction has made of steel, which is usually from angles and walls made of plexiglas with a width of ten $\mathrm{mm}$ for reflection the current performance (Errico et al., 2019). After ingoing the current in to the conduit and regulate the degree by numerical current meter over a distance of about two meters current reaches to the opening of the ramparrow seems (Chan et al., 2019).

It should be stated the quantity of current degree in this examination by an electronic current meter with 
exactness three zero (thousand) liters per second was completed through devices to split Sixty-three millimeter d related to incoming river that linked to the flume (Errico et al., 2019). To deliberate the current of aquatic at the beginning of flume applied from a square dish completed from fiber size of $80 * 80 \mathrm{~cm}$ on the superficial of the current water. Throughout gradient that under three dissimilar coarseness dimensions and a smooth plate was experienced in all trials were persistent and equivalent to $0.8 \mathrm{~cm}$. After passing the slope superficial with remoteness of $3.5 \mathrm{~m}$ has the current reached to the culmination of the flume and lastly detached from valve terminal. In Fig. 1 conduit strategy $(80 \mathrm{~cm})$, its apparatus and the site of the sloping plane and in Fig. 2 and 3. The method value penetration by point meter are exposed. It was applied from three dissimilar gradient and spicy (20, 30 and $35 \%$ ). At each were fixed phase of the gradient and a vertical modification for backrest to stop inflowing water in to the bottom of a steep and extensive it by hydraulic compression of aquatic, that in terms of the physical procedure of the prototypical is as a kind of perpendicular wedge. In addition to on the angles between perpendicular plate and gradient plate it's formed a compressed plastic tubing with a diameter of one centimeter to a climactic and the same situations for water current on gradient and evade break the current of water was located. It is important that all the perimeter of the wedge is closed by paste aquarium to avoid the error discharge (current degree) (Chang et al., 2010). First trials connected to the flat panel is done in dissimilar current degree, then the steep panel dry and the favorite coarseness plane which superficial coarseness quantified by siftings for each coarseness size have been consistently sized and devoted to procedure compressed iron by glue on a plastic plate with a width of about three millimeter or less. Then, it has steadied on the screen tilted by a drop of glue and aquarium so as to avoid it from affecting current and instigating errors owing to current passing flow rate amongst the gradient and flexible screen under coarseness. Then advanced to turn on the pump and rise inflow release to incoming the flume by the inlet valve. Subsequently confirming that the desired current degree and current situations is persistent, level of water were measured in a square network of sixteen facts on the adjacent and length by the depth point with a accuracy of one millimeter. The outstanding object is that procedures are taken vertical to horizontal plane, then the gradient design in individually prototypical was used to the information. The three kinds of aggregate with three dissimilar dimensions were applied as coarseness. Trials were completed for each of the gradient of 35, 30 and $20 \%$, with five rate $0.8,1.6,2.4,3.2$ and 4 liters per second and three coarseness in size 2,1.5and 1 millimeter that in the Table 1 (Abrahams and Parsons, 1994).

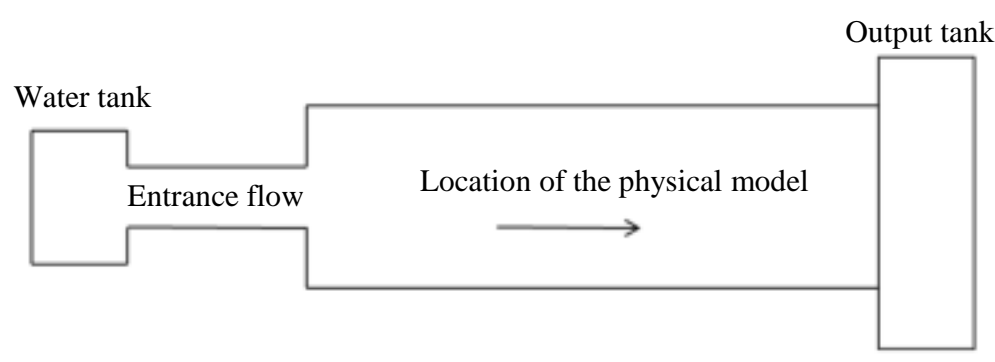

Fig. 1: The plan of flume laboratory in this study

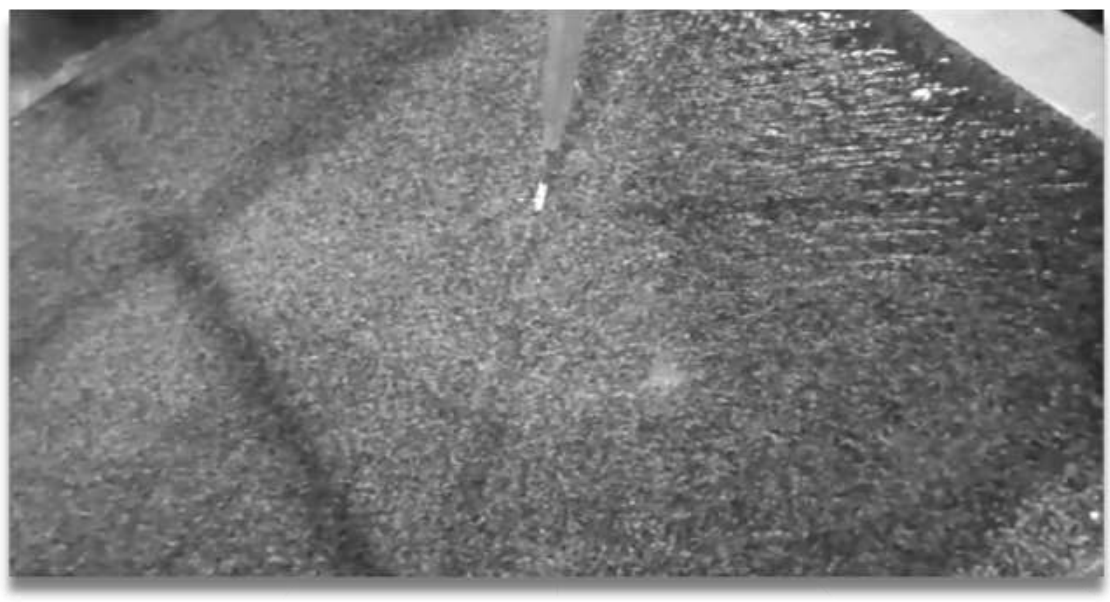

Fig. 2: The way measure depth by point meter 


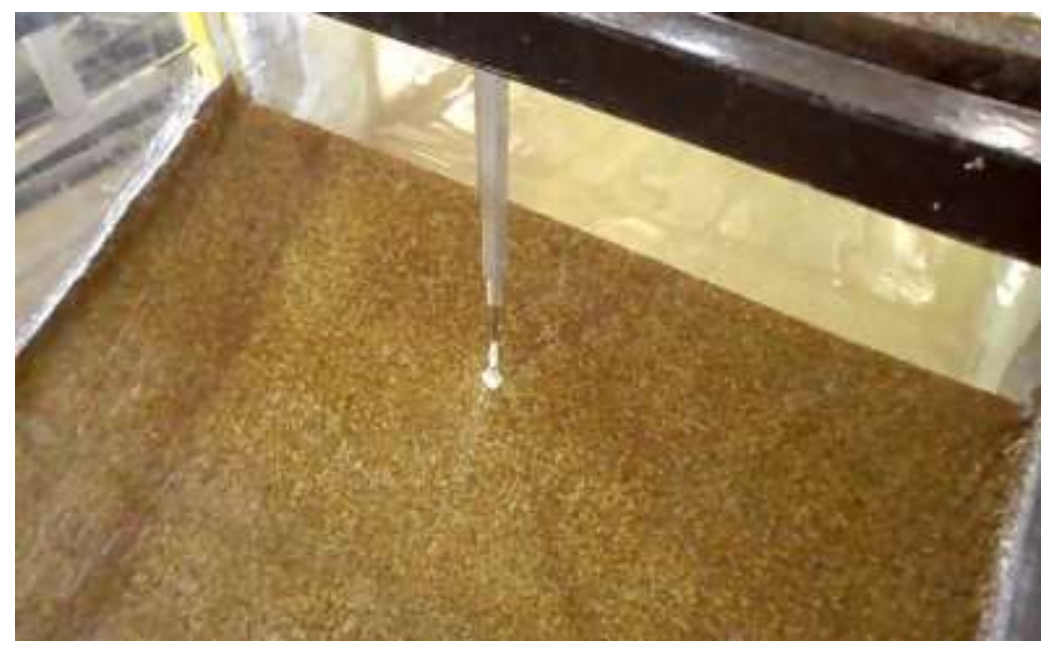

Fig. 3: The way measure depth by point meter

Table 1: Model specifications made in the laboratory

\begin{tabular}{llll}
\hline Rows & Slope $(\%)$ & Type bed roughness & During hot water wanting \\
\hline 1 & 20 & Flat & 80 \\
2 & 20 & Roughness $2 \mathrm{~mm}$ Roughness $1.5 \mathrm{~mm}$ & 80 \\
3 & 20 & Roughness $1 \mathrm{~mm}$ & 80 \\
4 & 20 & Flat & 80 \\
1 & 30 & Roughness $2 \mathrm{~mm}$ Roughness $1.5 \mathrm{~mm}$ & 80 \\
2 & 30 & Roughness $1 \mathrm{~mm}$ & 80 \\
3 & 30 & & 80 \\
4 & 30 & Flat & 80 \\
1 & 35 & Roughness 2 mm Roughness $1.5 \mathrm{~mm}$ & 80 \\
2 & 35 & Roughness 1 mm & 80 \\
3 & 35 & & 80 \\
4 & 35 & & 80 \\
\hline
\end{tabular}

In view of that current degree was persistent and arbitrary in challenging situations, the current degree unit on the width of $80 \mathrm{~cm}$ in the flume set defined and similarly water level were quantified long ways and diagonally on sixteen points. From average size of the elevation to become the current degree depend on the steadiness association was applied as surveys (Ayub et al., 2005):

$$
\frac{Q}{b}=V y
$$

$$
V=\frac{q}{y}
$$

To attain the result of Manning coarseness factors (n) value of these components by flexible components in the trial from experiential formula Manning, conferring to figures gained from the examination was applied as surveys (Azamathulla and Jarrett, 2013):

$$
A=\frac{1}{n} * s^{0.5} *\left(\frac{A}{p}\right)^{\left(\frac{2}{3}\right)}
$$

$$
\begin{aligned}
& n=s^{0.5} *\left(\frac{A}{p}\right)^{\left(\frac{2}{3}\right)} / V \\
& f=\frac{R^{2 / 3} \cdot S^{1 / 2}}{\vartheta}
\end{aligned}
$$

The Manning's $n$ values prearranged for highland show a perfect correlation with gradient angle.

It was well-defined the average current rapidity as (Bakry, 1992):

$V=\frac{Q}{\Omega}$

where, $V$ is the average current velocity, $Q$ is the measured discharge, $\Omega$ is the current region. By applying the energy design for frequently dissimilar steady current amongst two dissimilar portions, we attained (Bakry, 1992):

$$
Z_{2}+h_{2}+\frac{V_{2}^{2}}{2 g}-Z_{1}-h_{1}-\frac{V_{1}^{2}}{2 g}=L \frac{V_{m}^{2}}{C^{2} R_{m}}
$$


where, $Z_{i}$ is the bed height, $h i$ is the water depth, $V_{i}$ is the current rapidity at parts $i=1,2, V_{m}$ is the average current rapidity amongst the two parts, $R_{m}$ is the average hydraulic radius, $L$ is the channel length, $C$ is the Chezy amount, which consistent with the Manning formula can be measured as (AKM and Suzuki, 1988):

$C=\frac{1}{n} R_{m} \frac{1}{6}$

By replacing Equation (9) in Equation (10), we attain:

$$
Z_{2}+h_{2}+\frac{V_{2}^{2}}{2 g}-Z_{1}-h_{1}-\frac{V_{1}^{2}}{2 g}=L \frac{V_{m}^{2}}{\left(\frac{1}{n} R_{m} \frac{1}{6}\right)^{2}}
$$

where the Manning's $n$ is the basically measure that is unidentified, temporarily all the other factors were improved from field numbers. Thus, it was possible to describe the Manning quantity for the investigational section, accompanied by the following relation (Errico et al., 2018):
$n=\sqrt{\frac{Z_{2}+h_{2}+\frac{V_{2}^{2}}{2 g}-Z_{1}-h_{1}-\frac{V_{1}^{2}}{2 g}}{L}} \cdot \frac{R^{\frac{2}{3}}}{V_{m}}=\frac{J^{\frac{1}{2}} R_{m}^{\frac{2}{3}}}{V_{m}}$

where, $J$ is the slope of the total energy line (Kirby et al., 2005).

In the drainage gradient and runoff trials the current is persistent and steady and consequently, the manning quantity can be planned on separately investigational route as:

$n=\frac{h^{2 / 3} \sqrt{i}}{Q}=\frac{h^{5 / 3} B \sqrt{i}}{Q}$

$n=\frac{h^{2 / 3} \sqrt{i}}{u}=\frac{h^{5 / 3} B \sqrt{i}}{Q}$

$n=\frac{h^{2 / 3} \sqrt{i}}{u}=\frac{h^{5 / 3} B \sqrt{i}}{Q}$

where, $B$ is the waterfall width, $Q$ is the water discharge, $i$ is the longitudinal slope and $h$ is the quantified water depth.

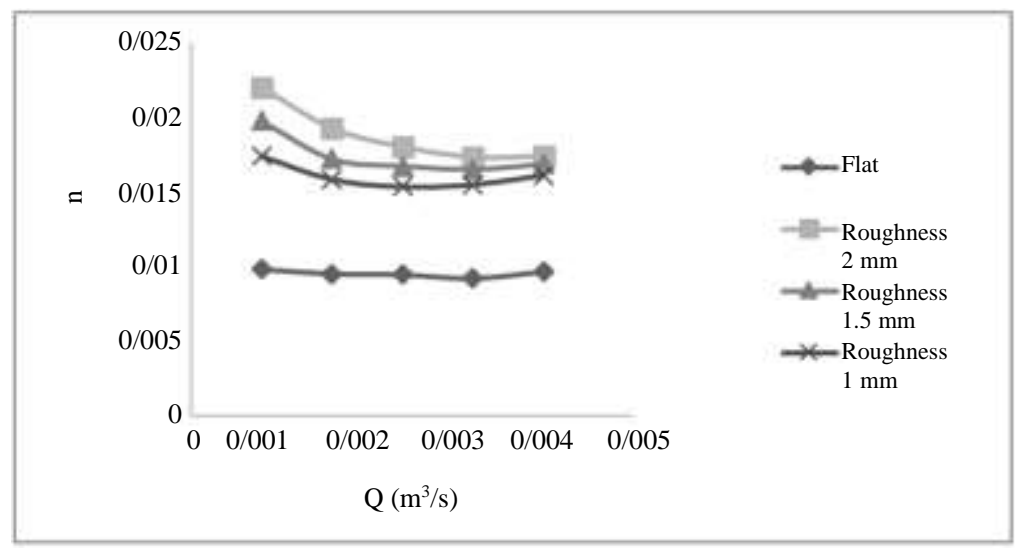

Fig. 4: The change of Manning resistance coefficient against changes in flow rate based on the total average depth for $20 \%$ slope

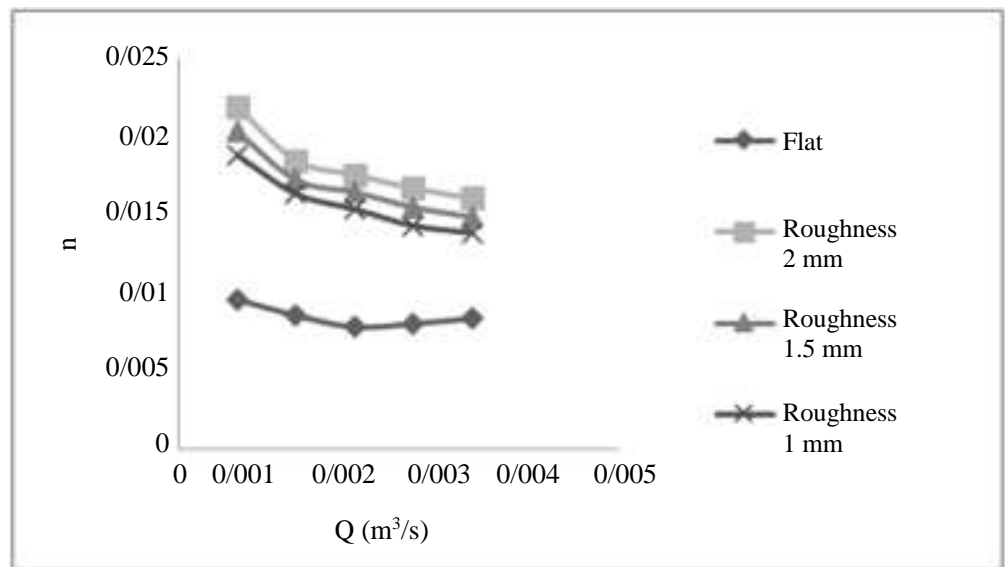

Fig. 5: The change of Manning resistance coefficient against changes in flow rate based on the total average depth for $30 \%$ slope 


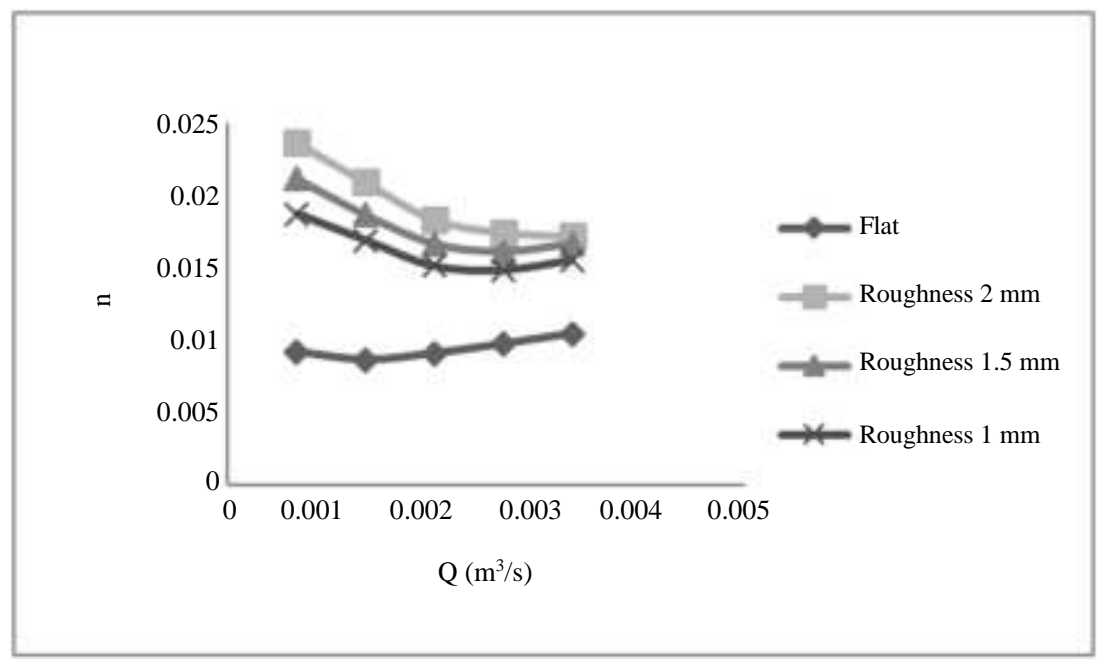

Fig. 6: The change of Manning resistance coefficient against changes in flow rate based on the total average depth for $35 \%$ slope

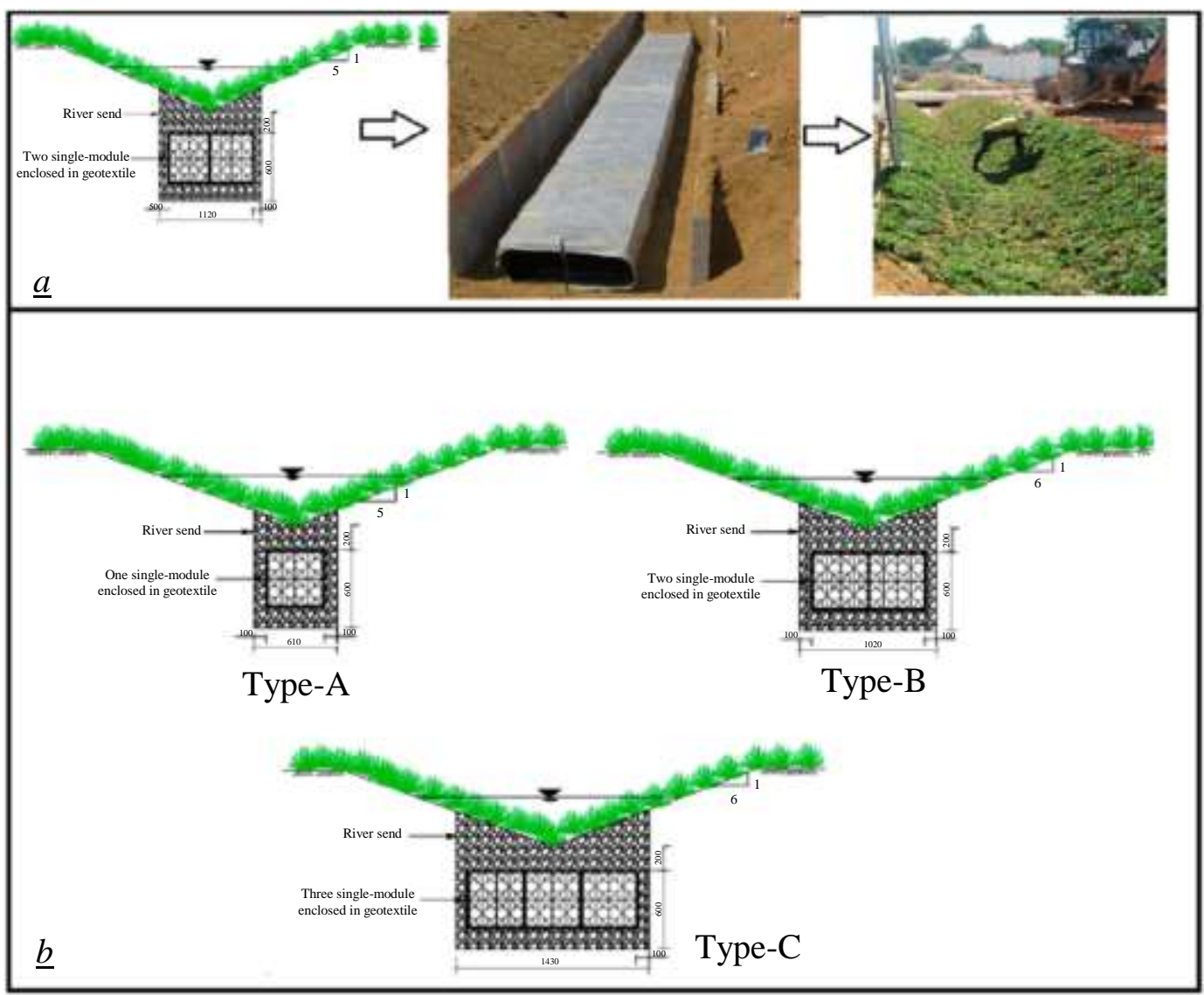

Fig. 7: Three kinds of environmental subsurface model (Zakaria et al., 2003; Mohammadpour et al., 2020)

Figure 4 shows the alteration of Manning persistence factor in contradiction of variations in current degree depend on the overall average depth for $20 \%$ gradient. Figure 5 shows the variation of Manning persistence factor in contradiction of variations in current degree depend on the over-all average depth for $30 \%$ gradient. Figure 6 shows the variation of Manning persistence factor in contradiction of variations in current degree depend on the over-all average depth for $35 \%$ gradient. Figure 7 shows three types of ecological subsurface prototypical. 


\section{Results}

The aim of this examination is essentially the consequence of sharp gradients in mountainous regions and the measurement of the coarseness of the floor consistent with the grade measured on the Manning coarseness constant.

The inconstant components measured included: The penetration of the water current at sixteen points for a organization of longitudinal and sloping Square. Conversely, the three adaptable gradients, five flexible degrees, three flexibles size bed deposit and a flat superficial were accomplished sixty and frequent three times for every investigation and we had one hundred and eighty trials sets. In the conclusion the grade figures that include depth, rapidity, gradient and coarseness differences of the coarseness factors were accomplished as surveys.

Conferring to Strickler association the Manning coarseness factor for $n$ is $n=0.0417 K_{s}^{\left(\frac{1}{6}\right)}$, where $K_{s}$ is the coarseness height in meters, coarseness to be $1 / 6$ the dimensions of the coarseness has a straight the association.

It was originated experimental connections, which signify the association between Manning roughness and particle size. In this study, as quantified in the plans, the Manning roughness is enlarged by cumulative the size of the roughness specifies a straight the relationship. Similarly, consistent with Manning, Manning roughness has an inversely association with the rapidity. Similarly, a straight relationship between the measurement of the current and the current rapidity is documented. Consequently, as can be realized in the figures: by collective the current grade distended rapidity and reduced Manning coarseness. But then again with increasing current grade noticed the recognized stream grade that the diverse proportions of differs gradient the amount of this reduction and the significant modification in the Manning coarseness constant condensed and make to a moderately persistent. Gradient table has a straight relation to the quantity of coarseness and in (35\%) gradient have the maximum quantity of coarseness. The assumption and endorsements fundamentally if only a narrow mountain currents as runoff from precipitation in these zones to examine, Considerable alteration to rise the Manning coarseness constant and therefore decrease the conservational degradation that is the important determinations cannot be required. Then normally in sharp mountainous regions of shallow streams can be used degree regulate constructions and by dropping current and so regulate the depth and rapidity on hydraulic persistence enhanced. Consequently, decrease corrosion degrees, as a significance of the measurement of deposit transportation and origin problems in downstream units similarly declines. The effects of gradient and coarseness are combined, makes a valued evaluation of drainage slant. If separately coarseness and gradient are identified then the extra association can be used to calculate drainage gradient with superior precision. The technique of boundaries amongst data for places where drainage concentration is connected with either superficial, channel opening by overland current, or no visible geomorphic significance is stable with theoretically created drainage area-gradient relations. Hydrological and soil erosion mockups require projects of current rapidity, for which any the Darcy-Weisbach or the Manning design is generally used. A categorization of field researches was surveyed in a negligeable catchment to reach reliable values of Manning's n. The experimental were exposed for a diversity of terrestrial measures as well as for varied gradient attitudes. There is an artificial linear rise in Manning's $n$ (and $f$ ) with increasing gradient method. As Manning's $n$ is regularly expected to be defined, this must slow that furthermore quickness rises with gradient or hydraulic radius decreases. The magnitudes offered closely no increase in rapidity and an unimportant intensification in hydraulic radius with gradient, as current was more fixated on sharpy gradients. Possible descriptions for this absence of strengthening in rapidity include distended coarseness, condensed real gradient angle in spite of the development of vertical head cuts and a adjustment in energy procedure. The progress of Manning's $n$ with gradient signifies that, in soil corrosion samples using Manning's scheming, the evaluation of $n$ (or $f$ ) should be a determination of the grade for erodible soils. For nonerodible soil no increase in Manning's n with gradient was perceived. Hydrological and soil erosion prototypes requisite to compute the stream rapidity to be capable of pretend the stream of water over the aquatic superficial. These prototypes usually apply a distinct water equilibrium for every spatial component, wherein the water depth accessible for overflow is designed by deducting interception, penetration and superficial loading from rainfall. Numerous calculations are accessible to compute highland stream rapidity after this water penetration. The greatest extensively applied of these calculations are the Darcy-Weisbach and Manning calculations. Greatest workshop investigations on highland current appear to apply the Darcy-Weisbach $f$, while most investigations of current use Manning's $n$. Stream penetration and rapidity will then be decidedly inconstant in space. It was investigated Darcy-Weisbach $f$ for desert hill slopes and found that it varies with the rate of flow. Meanwhile the degree of current is extremely inconstant in place, so also is $f$. Persistence to current will similarly be inconstant in period, as it be contingent on constantly altering stream situations. This necessity is regularly examined by evolving associations between the Darcy-Weisbach $f$ and Reynolds number. It has been distinguished, Manning's $n$ is probable to perform in the similar method as $f$. Similarly, it has been 
displayed that there are not merely interactions between $\operatorname{Re}$ and $f$, then similarly between $\operatorname{Re}$ and $\mathrm{n}$ and between $\operatorname{Re}$ and Chezy $C$. The current will similarly incline to focus on the down-slope way, which is probable to reduce persistence to current in that way. The goals of the investigation plan defined in this article were the subsequent. To assess the usage of Manning's calculation for sharp slopes. For this determination, Manning's $n$ was dignified on slopes fluctuating from different gradient. To realize if Manning's calculation can be applied or if the Darcy-Weisbach calculation is more appropriate owing to its correlation with Reynolds quantity. The standards acquired for diverse terrestrial usages and slopes were planned to be applied as input for soil corrosion prototypes.

\section{Discussion}

Manning's $n$ is frequently measured a persistent, consequently the enquiry ascends what triggered this superficial intensification of Manning's $n$ with gradient. Explanations throughout the experimentations displayed that, on steeper slopes, the stream determined and stream corrosion happened.at the variety of discharges applied in the trials, this lead to in an enlarged rate of $R$ owing to current application. The corrosion degrees evidently enlarged with cumulative slope approaches. Also, it was detected that stream rapidity scarcely amplified with cumulative gradient angles. The consequence of slope might be decreased for hydraulically rough superficial. An amplified corrosion degree with cumulative slope might cause in enlarged roughness. There is an actual rise in roughness with cumulative slope approaches, then their trials do not display whether or not this rise is satisfactory to clarify the absence of rise in rapidity with gradient direction. The environmental subsurface component is the chief portion of the ecological organization to achieve rainstorm water, contamination and runoff in city zones. It was considered to deliberate total porosity $(\mathrm{Pt})$ and the number of modules $(\mathrm{mt})$ for approximation of Manning's roughness in the sectional waterway. The environmental subsurface model is used to diverse ecological organizations to achieve storm water, contamination and runoff in city zones. Throughout the rainstorm water runoff, the particulate contaminant is engaged by flora and permeable broadcasting at the highest of the component. Later, the component transports the current into downstream and at the similar period, the current infiltrates into enclosed stones and foods the groundwater. The usage of subsurface component in town zones shows a main part in governing the contamination town overflows owing to better ecological maintainability. In the subsurface model, the drainage cells deception water at the basis wherever it can be reserved in the drainage model. By amassing polluted runoff at the foundation, the current release is decreased from upstream to downstream subsequent in contaminants and poisonous substances not settled into the surroundings. The subsurface models were suggested by the River Engineering as the foremost portion of Bio-Environmental Drainage Schemes and maintainable town drainage organization to achieve both water capacity and value in urban and manufacturing zones. In environmental, approximation of the roughness quantity is a compound difficult owing to the result of the subsurface model on the three-D current. The environmental grassland contains of a network with grassland, subsurface models and penetrable geotextile resources. It was stated that the subsurface model roughness is the chief factor applied to project environmental which impact both flow decrease and refinement. It was presented that reduction of runoff current in model channel endorses contaminant elimination. The Manning's roughness constant $(n)$ is optional as an important component to guess roughness in dissimilar stations.

\section{Acknowledgement}

This research was supported by the Isfahan University of the Technology. We thank our all authors who provided insight and expertise that greatly assisted the research.

\section{Funding Information}

This paper is part of several studies of a group of Researchers, Professors and students of Civil Engineering from Iran. The research group does not receive any funding to support it.

\section{Author's Contributions}

All authors contributed to design the study, write and revise the manuscript.

\section{Ethics}

The present Study and ethical aspect were approved by the Isfahan University of the Technology. The present study was approved by the Isfahan University of Technology.

\section{References}

Abrahams, A. D., \& Parsons, A. J. (1994). Hydraulics of interrill overland flow on stone-covered desert surfaces. Catena, 23(1-2), 111-140.

AKM, R., \& Suzuki, S. (1988). Flow retardance in open channels due to artificial flexible vegetation. Journal of Irrigation Engineering and Rural Planning, 1988(13), 5-17. 
Ayub, K. R., Sidek, L. M., Ainan, A., Zakaria, N. A., Ghani, A. A., \& Abdullah, R. (2005). Storm water treatment using bio-ecological drainage system. International Journal of River Basin Management, 3(3), 215-221.

Azamathulla, H. M., \& Jarrett, R. D. (2013). Use of geneexpression programming to estimate Manning's roughness coefficient for high gradient streams. Water resources management, 27(3), 715-729.

Bakry, M. F. (1992). Effect of submerged weeds on the design: Procedure of earthen Egyptian canals. Irrigation and Drainage systems, 6(3), 179-188.

Chan, N. W., Tan, M. L., Ghani, A. A., \& Zakaria, N. A. (2019, April). Sustainable urban drainage as a viable measure of coping with heat and floods due to climate change. In IOP Conference Series: Earth and Environmental Science (Vol. 257, No. 1, p. 012013). IOP Publishing.

Chang, T. H., Huang, S. T., Chen, S., \& Lai, J. C. (2010). Estimation of manning roughness coefficients on precast ecological concrete blocks. Journal of Marine Science and Technology, 18(2), 308-316.

Chen, Y. C., Kao, S. P., Lin, J. Y., \& Yang, H. C. (2009). Retardance coefficient of vegetated channels estimated by the Froude number. Ecological Engineering, 35(7), 1027-1035.

Chow, V. T. (1959), Open-Channel Hydraulics. McGraw-Hill, New York.

Conesa-García, C., Sánchez-Tudela, J. L., Pérez-Cutillas, P., \& Martínez-Capel, F. (2018). Spatial variation of the vegetative roughness in Mediterranean torrential streams affected by check dams. Hydrological Sciences Journal, 63(1), 114-135.
Dash, S. S., \& Khatua, K. K. (2016). Sinuosity dependency on stage discharge in meandering channels. Journal of Irrigation and Drainage Engineering, 142(9), 04016030.

Emmett, W. W. (1970). The hydraulics of overland flow on hillslopes (Vol. 662). US Government Printing Office.

Errico, A., Lama, G. F. C., Francalanci, S., Chirico, G. B., Solari, L., \& Preti, F. (2019). Flow dynamics and turbulence patterns in a drainage channel colonized by common reed (Phragmites australis) under different scenarios of vegetation management. Ecological Engineering, 133, 39-52.

Errico, A., Pasquino, V., Maxwald, M., Chirico, G. B., Solari, L., \& Preti, F. (2018). The effect of flexible vegetation on flow in drainage channels: Estimation of roughness coefficients at the real scale. Ecological engineering, 120, 411-421.

Kirby, J. T., Durrans, S. R., Pitt, R., \& Johnson, P. D. (2005). Hydraulic resistance in grass swales designed for small flow conveyance. Journal of Hydraulic Engineering, 131(1), 65-68.

Mohammadpour, R., Zainalfikry, M. K., Zakaria, N. A., Ghani, A. A., \& Weng Chan, N. (2020). Manning's roughness coefficient for ecological subsurface channel with modules. International Journal of River Basin Management, 18(3), 349-361.

Zakaria, N. A., Ab Ghani, A., Abdullah, R., Mohd. Sidek, L., \& Ainan, A. (2003). Bio-ecological drainage system (BIOECODS) for water quantity and quality control. International Journal of River Basin Management, 1(3), 237-251. 